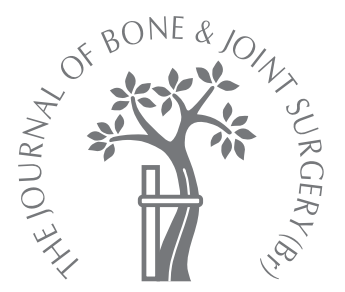

\title{
Oxford medial unicompartmental knee arthroplasty in patients younger and older than 60 years of age
}

\begin{abstract}
A. J. Price,
C. A. F. Dodd,

U. G. C. Svard,

D. W. Murray
\end{abstract}

From Nuffield

Orthopaedic Centre, Oxford, England

A. J. Price, DPhil,

FRCS(Orth), Clinical Lecturer, Honorary Consultant

C. A. F. Dodd, FRCS,

Consultant Orthopaedic

Surgeon

D. W. Murray, MD,

FRCS(Orth), Professor of

Orthopaedic Surgery

Nuffield Department of

Orthopaedic Surgery

Nuffield Orthopaedic Centre,

Headington, Oxford OX3

7LD, UK.

U. G. C. Svard, MD,

Consultant Orthopaedic

Surgeon

Department of Orthopaedic

Surgery

Skaraborgs Sjukhus

Kärnsjukhuset, 45185

Skövde, Sweden.

Correspondence should be sent to Mr A. J. Price; e-mail: andrew.price@ndos.ox.ac.uk

@2005 British Editorial

Society of Bone and

Joint Surgery

doi:10.1302/0301-620X.87B11. $16324 \$ 2.00$

$J$ Bone Joint Surg $[\mathrm{Br}]$ 2005;87-B:1488-92.

Received 24 January 2005;

Accepted after revision

24 May 2005

We present a comparison of the results of the Oxford unicompartmental knee arthroplasty in patients younger and older than $\mathbf{6 0}$ years of age. The ten-year all-cause survival of the $<60$ years of age group (52) was $91 \%(95 \%$ confidence interval (Cl) 12), while in the $\geq 60$ years of age group (512), the figure was $96 \%(95 \% \mathrm{Cl} 3)$. For the younger group, the mean Hospital for Special Surgery score at ten-year follow-up $(n=21)$ was 94 of 100, compared with a mean of $\mathbf{8 6}$ of $\mathbf{1 0 0}$ for the older group $(n=135)$. The results show that the Oxford unicompartmental arthroplasty can achieve ten-year results that are comparable to total knee arthroplasty in patients $<60$ years of age. We conclude that for patients aged over 50 , age should not be considered a contraindication for this procedure.

There is continuing debate regarding the best treatment for young patients with unicompartmental osteoarthritis of the knee. ${ }^{1}$ There are very few published studies of unicompartmental knee replacement (UKA) in young osteoarthritic patients. Concern exists as to the durability of UKA in this age group. ${ }^{2-4}$ As a result, young age is considered by many to be a contraindication to this procedure. $^{5}$

The Oxford unicompartmental knee arthroplasty (Biomet Ltd, Bridgend, UK) is a mobilebearing prosthesis. Recent studies have shown that good clinical outcomes can be achieved with the Oxford UKA in patients with medial compartment disease. ${ }^{6-9}$ There are no published results for the use of this prosthesis in younger patients specifically.

The aim of this study was to determine the ten-year survival and clinical outcome of the Oxford UKA in patients with anteromedial osteoarthritis who were $<60$ years of age at operation and to compare the results with those of patients $\geq 60$ years of age.

\section{Patients and Methods}

Data was obtained from two centres, which have both published their results previously. In Oxford, at the Nuffield Orthopaedic Centre, between 1982 and 1992, 144 knees (114 patients) with primary anteromedial osteoarthritis were treated with an Oxford UKA. ${ }^{6,10}$ In Skövde, Sweden, between 1983 and 2000, 420 knees (333 patients) were similarly treated for the same condition. ${ }^{11}$ All patients had primary osteoarthritis of the medial compartment with full thickness lateral compartment articular cartilage and an intact anterior cruciate ligament. Fixed flexion of more than $15^{\circ}$ and a non-correctable varus deformity were exclusion criteria. Cartilage loss in the patellofemoral joint was not considered a contraindication. The two series of patients were wellmatched in terms of age and gender (Table I). Combining the two series produces a homogeneous group of 564 medial Oxford UKAs and this group provides the basis for our study. There were 447 patients, with 258 women and 189 men. The mean age was 70 years (34.6 to

Table I. Details of patient groups

\begin{tabular}{lllcl}
\hline & $\begin{array}{l}\text { Number of } \\
\text { knees }\end{array}$ & $\begin{array}{l}\text { Number of } \\
\text { patients }\end{array}$ & Men:women & Mean age in yrs (SD; range) \\
\hline Oxford series $^{6,10}$ & 144 & 114 & $53: 61$ & $70.5(8.0 ; 34.6$ to 90.6$)$ \\
Skövde series $^{11}$ & 420 & 333 & $136: 197$ & $69.8(7.4 ; 50.7$ to 94.5$)$ \\
$\begin{array}{l}\text { Combined series } \\
\quad \text { Total }\end{array}$ & 564 & 447 & $189: 258$ & $70 \quad(7.5 ; 34.6$ to 94.5$)$ \\
$\quad<60$ years of age & 52 & 44 & $15: 29$ & $56.4(3.8 ; 34.6$ to 59.6$)$ \\
$\quad \geq 60$ years of age & 512 & 403 & $174: 229$ & $71.4(6.3 ; 60.1$ to 94.5$)$ \\
\hline
\end{tabular}


Table II. Details of the revision procedures

\begin{tabular}{|c|c|c|c|c|}
\hline Case & Age (yrs) & $\begin{array}{l}\text { Time to revision } \\
\text { (yrs) }\end{array}$ & Indication & Procedure \\
\hline \multicolumn{5}{|c|}{$<60$ years of age group } \\
\hline 1 & 51.6 & 7.8 & Arthritis in lateral compartment & Revision to TKA* \\
\hline 2 & 54.5 & 6.8 & Loose femoral component & Revision to TKA \\
\hline 3 & 56.0 & 5.4 & Fracture of meniscus & Open bearing-exchange \\
\hline 4 & 58.2 & 10.2 & Arthritis in lateral compartment & Revision to TKA \\
\hline \multicolumn{5}{|c|}{$<60$ years of age group } \\
\hline 1 & 60.6 & 4.6 & Arthritis in lateral compartment & Revision to TKA \\
\hline 2 & 64.5 & 1.1 & Arthritis in lateral compartment & Revision to TKA \\
\hline 3 & 65.6 & 4.3 & Arthritis in lateral compartment & Revision to TKA \\
\hline 4 & 67.5 & 4.0 & Arthritis in lateral compartment & Revision to TKA \\
\hline 5 & 69.7 & 1.4 & Arthritis in lateral compartment & Revision to TKA \\
\hline 6 & 70.3 & 3.9 & Arthritis in lateral compartment & Revision to TKA \\
\hline 7 & 74.6 & 4.5 & Arthritis in lateral compartment & Revision to TKA \\
\hline 8 & 86.6 & 0.7 & Arthritis in lateral compartment & Revision to TKA \\
\hline 9 & 64.4 & 5.6 & Loose femoral and tibial components & Revision to TKA \\
\hline 10 & 68.6 & 5.8 & Loose femoral and tibial components & Revision to TKA \\
\hline 11 & 65.7 & 10.0 & Loose femoral component & Revision to TKA \\
\hline 12 & 81.7 & 1.6 & Loose femoral component & Revision of femoral component \\
\hline 13 & 72.4 & 5.9 & Bearing dislocation/loose femoral component & Revision to TKA \\
\hline 14 & 65.6 & 0.3 & Bearing dislocation & Open bearing-exchange \\
\hline 15 & 66.1 & 3.7 & Bearing dislocation & Revision to TKA \\
\hline 16 & 72.5 & 3.9 & Bearing dislocation & Revision to TKA \\
\hline 17 & 67.4 & 1.2 & Deep infection & Revision to TKA \\
\hline 18 & 68.6 & 0.5 & Deep infection & Revision to TKA \\
\hline 19 & 75.4 & 2.2 & Deep infection & Revision to TKA \\
\hline 20 & 67.3 & 12.5 & Pain, unexplained at operation & Revision to TKA \\
\hline
\end{tabular}

* TKA, total knee arthroplasty

94.5). The patients were divided into two subgroups; 1 ) those $\geq 60$ years of age at surgery ( 512 knees) and 2 ) those $<60$ years of age at surgery ( 52 knees). All but one of those $<60$ years were aged between 50 and 60 years.

The medial Oxford UKA has a spherical femoral component and a flat tibial component, between which a fullycongruent unconstrained meniscal bearing is implanted. In 1979 , the prosthesis was modified (phase 2), with the introduction of new instruments and changes to the nonarticular shape of the femoral component. In 1999, phase 3 was introduced with changes to the instrumentation that facilitated the insertion of the prosthesis through a short incision, without dislocation of the patella. For phase 1 and 2 the prosthesis was inserted through a medial parapatellar approach, with dislocation of the patella to gain exposure of the joint. Phase 1 prostheses were used in 177 procedures, phase 2 prostheses in 352 and phase 3 prostheses in 35. All patients were given the same guidelines regarding post-operative activities. The younger patients, for whom post-operative activity was likely to be greater, were advised to avoid contact sports and downhill skiing.

For the survival analysis, all patients were contacted to establish whether their UKA had been revised. Where patients had died, the status of their knee at the time of death was established from hospital and general practitioner notes and through contact with relatives. One patient was lost to follow-up. The ten-year survival was calculated from a life-table using revision for any cause as the endpoint. We calculated $95 \%$ confidence intervals (CI) using the method described by Peto et al. ${ }^{12}$ Statistical comparison between groups was then performed using a log rank test.

At the time of the study, there were 21 knees in 19 patients from those $<60$ years of age whose follow-up was a minimum of ten years. All these patients had been reviewed using the Hospital for Special Surgery (HSS) knee score. ${ }^{13}$ Using this system the scores were graded as: poor (< 60 points), fair (60 to 69 ), good (70 to 84 ) or excellent (85 to 100). These results were compared with data from 133 knees (105 patients) in those older than 60 years of age with a minimum ten-year follow-up. Within this cohort, seven knees (seven patients) were not reviewed because of ill health or failure to attend for assessment. Comparison was made between the two groups using a Student's $t$-test. Values for $\mathrm{p}<0.05$ were regarded as significant.

Radiographic review was performed for 20 of the 21 knees in those aged $<60$ years of age. Radiographs were assessed for migration or subsidence of the components, or osteoarthritic change in the retained compartments. ${ }^{14}$ The presence of stable peri-prosthetic radiolucent lines, which have been previously reported with this prosthesis and other unicompartmental devices, ${ }^{10,15,16}$ was also noted. The inter- and intra-observer errors for this type of assessment have previously been reported and show that the method is reliable. ${ }^{11}$ The radiographs were not long-leg radiographs and therefore a valid assessment of varus or valgus alignment was not possible. In addition, the preoperative radiographs were not available for comparison 


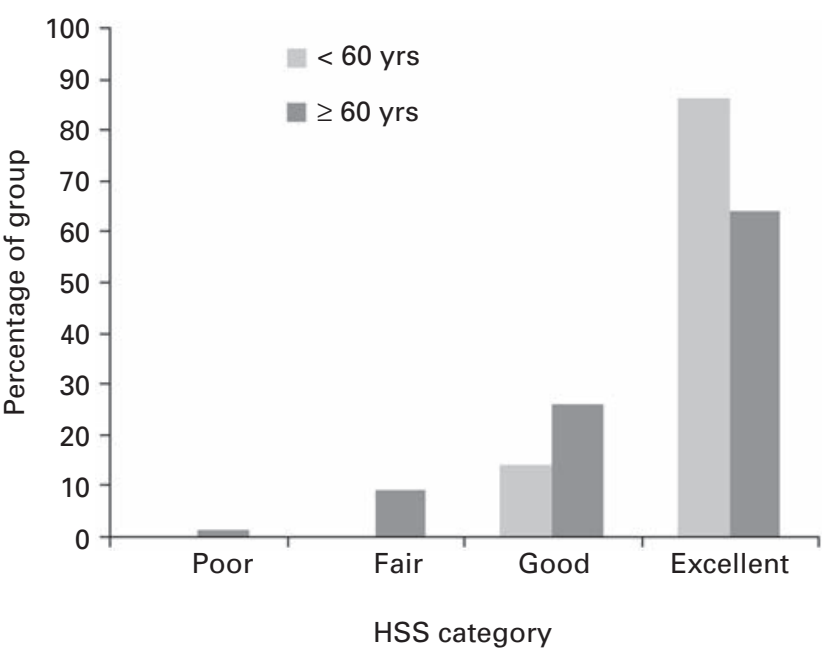

Fig. 1

Distribution of Hospital for Special Surgery (HSS) scores at follow-up of ten years.

with the ten-year radiographs. Comparison with the radiographic findings in those aged $\geq 60$ years of age was not possible because a significant proportion of the ten-year radiographs were not available for review.

\section{Results}

There were $24(4.3 \%)$ revisions in the total group of 564 knees. The indication and details of the revision procedures are given in Table II. There were $20(3.9 \%)$ revisions within those $\geq 60$ years of age and there were four $(7.7 \%)$ in those $<60$ years of age. No patient from either group was awaiting revision.

The ten-year survival for patients $\geq 60$ years of age was $96 \%$ (95\% CI 3.2, number at risk at ten years 157$)$ and for those $<60$ years of age the value was $91 \%$ (95\% CI 12.4 , number at risk at ten years 19) $(\log$ rank test; $\mathrm{p}=0.6)$.

The mean pre-operative HSS knee score for the patients $<60$ years of age was 52 (95\% CI 6) compared to a mean of 57 (95\% CI 2 ) in those $\geq 60$ years of age (Student's $t$-test; $\mathrm{p}=0.04)$. At ten years after surgery, the younger group had a higher mean HSS knee score of 94 (95\% CI 3), compared to $86(95 \%$ CI 2$)$ in those aged $\geq 60$ years of age (Student's $t$-test; $\mathrm{p}=0.001)$. The distribution of HSS grades are shown in Figure 1. In the young age group, $18(86 \%)$ were pain free, while the other three patients (three knees) reported mild pain. Despite a similar pre-operative mean range of movement $\left(109^{\circ}\right.$ and $\left.110^{\circ}\right)$, the range at ten years was $116^{\circ}$ in the younger group compared with $111^{\circ}$ in the older group (Student's $t$-test; $\mathrm{p}=0.08$ ).

Analysis of the radiographs showed that within those $<60$ years of age $55 \%$ of prostheses had stable radiolucent lines ( $\leq 1 \mathrm{~mm}$ thick) around the tibial component and one had a radiolucent line around the femoral component. In all cases, the radiolucency was seen in conjunction with a dense sclerotic line demarcating the limit of the radiolucency. However, no prosthesis showed focal osteolysis and none was considered radiographically loose. One knee had early lateral compartment osteoarthritis (Ahlbäck grade I), ${ }^{14}$ but the remaining 19 had no evidence of progression of disease.

\section{Discussion}

It has been suggested that the best candidates for UKA are older than 60 years of age with low activity levels. ${ }^{5}$ Published results of the Oxford medial UKA confirm that excellent results can be achieved in this age group, with ten-year survival of $95 \%$ to $98 \% .{ }^{6,7}$ However, there is debate regarding the use of UKA in younger patients with osteoarthritis. To our knowledge, this is the first study to compare the clinical results of UKA in young and old patients from within the same series.

The ten-year results show a survival of $91 \%$ and a mean HSS score of 92 for patients $<60$ years of age, suggesting that the Oxford medial UKA functions well and is durable when used in younger patients. However, the ten-year survival is less than the $96 \%$ recorded for those $\geq 60$. The difference, which did not reach statistical significance but does have clinical significance may reflect the increased demands that younger patients place on prosthetic implants. Most notably they spend a greater time walking compared with patients $\geq 60$ years of age. ${ }^{17}$ Increased physical activity in young compared with older patients, who have undergone UKA, may be facilitated by the superior ten-year knee scores achieved by younger patients. The mean HSS score at ten years was 7 points greater for the younger group, despite lower pre-operative scores.

Pennington et $\mathrm{al}^{4}$ reported a ten-year survival of $92 \%$ in a series of Miller-Galante UKAs. This is the only other detailed ten-year survival analysis of UKA in patients $<60$ years of age. These findings were more encouraging than those of Engh and McAuley, ${ }^{3}$ who found a seven-year survival of $86 \%$ and predicted a ten-year survival of $80 \%$ for the Brigham prosthesis. The Swedish Knee Arthroplasty Register found a ten-year survival rate of $83 \%$ in patients $<65$ years of age for the use of UKA for osteoarthritis. ${ }^{18}$ Data in this series included a wide range of at least nine different prostheses, including the Oxford UKA, and no data regarding patient selection or surgical experience were available.

There was only one patient $<50$ years of age in our study and, therefore, it does not offer any worthwhile insight into the results for patients $<50$ years of age. The results do, however, suggest that the prosthesis is durable through the first decade after implantation in patients who are in their fifties. Further study will be required to determine if the $91 \%$ survival is maintained beyond ten years. A retrieval study ${ }^{19}$ has shown that this device has a wear rate of about $0.02 \mathrm{~mm} / \mathrm{year}$ and in our study, with a maximum of 17 years follow-up, there were no failures obviously related to debris. This resistance to wear should protect the device 
from failure during the second decade. One patient aged 56 at the time of surgery required revision because of a fractured bearing. The bearing was $3.5 \mathrm{~mm}$ thick and the use of the thinnest bearings in younger patients should be avoided.

The mean ten-year HSS score for our young group of patients was 92, similar to the mean of 94 reported by Pennington et $\mathrm{al}^{4}$ for the Miller-Galante prosthesis. In the only other clinical study of UKA in younger patients (mean age 52 years), Schai et al $^{2}$ reported good results in 28 PFC unicompartmental arthroplasties, but the follow-up was relatively short with a mean of 40 months. These results suggest that UKA can produce excellent clinical results in this age group.

More than half of the prostheses reviewed radiographically showed evidence of a thin radiolucency around the tibial component, associated with a sclerotic margin. Tibrewal et $\mathrm{al}^{15}$ reported a series of 80 Oxford UKAs where $96 \%$ of cases had radiolucency around the tibial component. The majority of radiolucencies had formed within one year and all were associated, as in our series, with a dense sclerotic line. However, a previous radiographic study ${ }^{16}$ has suggested that a stable radiolucency can be considered a normal finding. Similar changes have been reported with other unicompartmental devices. ${ }^{16}$

Total knee arthroplasty (TKA) and high tibial osteotomy are alternative treatments for unicompartmental disease in the younger age group. The reported ten-year survival $(28 \%$ to $80 \%)$ and functional outcome for high tibial osteotomy are generally worse than those seen with UKA and TKA. ${ }^{20-28}$ Reports of TKA in this age group can be difficult to interpret if results from patients with different indications such as rheumatoid and osteoarthritis have been combined and, as with UKA, there are few reports of TKA performed specifically for osteoarthritis in patients $<60$ years of age..$^{29,30} \mathrm{~A}$ reported series of 108 TKAs implanted in patients $<55$ years of age with osteoarthritis showed a ten-year cumulative survival (all-cause revision) of $90 \%$ and a mean post-operative HSS score of $92 .{ }^{31}$ Similar postoperative HSS results were shown for a series of 68 knees. ${ }^{32}$ A study of patients $<40$ years of age showed an eight-year survival from aseptic loosening of $91 \% .^{33}$ The Swedish Knee Arthroplasty study reported the results of TKAs performed on patients $<65$ years of age with osteoarthritis and found a ten-year cumulative survival rate of about $90 \% .^{18}$ The results of our study suggest that the Oxford UKA can produce similar results to TKA in younger osteoarthritic patients. Patients can then benefit from the reduced morbidity and improved kinematic function of the UKA, when compared to TKA. ${ }^{34,35}$ There is some evidence that the Oxford UKA is an easier implant to revise when compared with TKA. This may be an important consideration for the younger patient who may require at least one revision in their lifetime. ${ }^{36}$

We believe that for people in their fifties, age is not a contraindication to using the Oxford UKA to treat patients with anteromedial osteoarthritis of the knee.
The author or one or more of the authors have received or will receive benefits for personal or professional use from a commercial party related directly or indirectly to the subject of this article. In addition, benefits have been or will be directed to a research fund, foundation, educational institution, or other nonprofit organisation with which one or more of the authors are associated.

\section{References}

1. Deshmukh RV, Scott RD. Unicompartmental knee arthroplasty for younger patients: an alternative view. Clin Orthop 2002;404:108-12.

2. Schai PA, Suh JT, Thornhill TS, Scott RD. Unicompartmental knee arthroplasty in middle-aged patients: a 2- to 6-year follow-up evaluation. J Arthroplasty 1998;13: 365-72.

3. Engh GA, McAuley JP. Unicondylar arthroplasty: an option for high-demand patients with gonoarthrosis. Instr Course Lect 1999;48:143-8.

4. Pennington DW, Swienchowski JJ, Lutes WB, Drake GN. Unicompartmental knee arthroplasty in patients sixty years of age or younger. J Bone Joint Surg [Am] 2003;85-A:1968-73.

5. Kozinn SC, Scott R. Unicondylar knee arthroplasty. J Bone Joint Surg [Am] 1989; 71-A:145-50.

6. Murray DW, Goodfellow JW, O'Connor JJ. The Oxford medial unicompartmental arthroplasty: a ten-year survival study. J Bone Joint Surg [Br] 1998;80-B:983-9.

7. Svard UC, Price AJ. Oxford medial unicompartmental knee arthroplasty: a survival analysis of an independent series. J Bone Joint Surg [Br]2001;83-B:191-4.

8. Robertsson O, Knutson K, Lewold S, Lidgren L. The routine of surgical management reduces failure after unicompartmental knee arthroplasty. J Bone Joint Surg $[\mathrm{Br}]$ 2001;83-B:45-9.

9. Emerson RH Jr, Hansborough T, Reitman RD, Rosenfeldt W, Higgins LL. Comparison of a mobile with a fixed-bearing unicompartmental knee implant. Clin Orthop 2002;404:62-70

10. Weale AE, Murray DW, Crawford R, et al. Does arthritis progress in the retained compartments after 'Oxford' medial unicompartmental arthroplasty?: a clinical and radiological study with a minimum ten-year follow-up. J Bone Joint Surg [Br] 1999; 81-B:783-9.

11. Price AJ, Waite JC, Svard UC. Long-term clinical results of the medial Oxford unicompartmental knee arthroplasty. Clin Orthop 2005;435:171-80.

12. Peto R, Pike MC, Armitage $\mathbf{P}$, et al. Design and analysis of randomized clinical trials requiring prolonged observation of each patient. II: analysis and examples. $\mathrm{Br} \mathrm{J}$ Cancer 1977;35:1-39.

13. Insall JN, Ranawat CS, Aglietti P, Shine J. A comparison of four models of total knee-replacement prostheses. J Bone Joint Surg [Am] 1976;58-A:754-65.

14. Ahlbäck S. Osteoarthritis of the knee: a radiographic investigation. Acta Radiol 1968;(Suppl-277):7-72.

15. Tibrewal SB, Grant KA, Goodfellow JW. The radiolucent line beneath the tibial components of the Oxford meniscal knee. J Bone Joint Surg [Br] 1984;66-B:523-8.

16. Argenson JN, Chevrol-Benkeddache Y, Aubaniac JM. Modern unicompartmental knee arthroplasty with cement: a three to ten-year follow-up study. J Bone Joint Surg $[A m] 2002 ; 84-A: 2235-9$.

17. Schmalzried TP, Szuszczewicz ES, Northfield MR, et al. Quantitative assessment of walking activity after total hip or knee replacement. J Bone Joint Surg [Am] 1998;80-A:54-9

18. Swedish Knee Arthroplasty Register. Annual report 2004. www.ort.lu.se/knee/ pdf/skar 2004 eng.pdf (accessed 23/06/05).

19. Psychoylos V, Crawford RW, O'Connor JJ, Murray DW. Wear of congruent meniscal bearings in unicompartmental knee arthroplasty: a retrieval study of 16 specimens. J Bone Joint Surg [Br] 1998;80-B:976-82

20. Berman AT, Bosacco SJ, Kirshner S, Avolio A Jr. Factors influencing long-term results in high-tibial osteotomy. Clin Orthop 1991;272:192-8.

21. Insall J, Joseph D, Msika C. High tibial osteotomy for medial osteoarthritis of the knee: a long-term follow-up study. J Bone Joint Surg [Br] 1984;66-B:1040-8.

22. Coventry $\mathbf{M}$, Ilstrup D, Wallrichs S. Proximal tibial osteotomy: a critical long-term study of eighty-seven cases. J Bone Joint Surg [Am] 1993;75-A:196-201.

23. Rudan J, Simurda M. Valgus high tibial osteotomy: a long-term follow up study. Clin Orthop 1991;268:157-60.

24. Weale AE, Newman JH. Unicompartmental arthroplasty and high tibial osteotomy for osteoarthritis of the knee: a comparative study with a 12- to 17-year follow-up period. Clin Orthop 1994;302:134-7.

25. Aglietti P, Rinonapoli E, Stringa G, Taviani A. Tibial osteotomy for the varus osteoarthritic knee. Clin Orthop 1983;176:239-51.

26. Naudie D, Bourne RB, Rorabeck CH, Bourne TJ. Survivorship of the high tibial valgus osteotomy: a 10- to 22-year followup study. Clin Orthop 1999;367:18-27. 
27. Matthews LS, Goldstein SA, Malvitz TA, Katz BP, Kaufer H. Proximal tibial osteotomy: factors that influence the duration of satisfactory function. Clin Orthop 1988;229:193-200.

28. Coventry M. Upper tibial osteotomy for osteoarthritis. J Bone Joint Surg [Am]1985; 67-A:1136-40.

29. Duffy GP, Trousdale RT, Stuart MJ. Total knee arthroplasty in patients 55 years old or younger: 10- to 17-year results. Clin Orthop 1998;356:22-7.

30. Hofmann AA, Heithoff DO, Camargo M. Cementless total knee arthroplasty in patients 50 years or younger. Clin Orthop 2002;404:102-7.

31. Diduch DR, Insall JN, Scott WN, Scuderi GR, Font-Rodriguez D. Total knee replacement in young, active patients: long-term follow-up and functional outcome. J Bone Joint Surg [Am] 1977;79-A:575-82.
32. Stern S, Bowen M, Insall J, Scuderi G. Cemented total knee arthroplasty for gonarthrosis in patients 55 years old or younger. Clin Orthop 1990;260:124-9.

33. Lonner JH, Hershman S, Mont M, Lotke PA. Total knee arthroplasty in patients 40 years of age and younger with osteoarthritis. Clin Orthop 2000;380:85-90.

34. Price AJ, Webb J, Topf H, et al. Rapid recovery after Oxford unicompartmental arthroplasty through a short incision. J Arthroplasty 2001:16:970-6.

35. Price AJ, Rees JL, Beard DJ, Gill HS, Dodd CAF, Murray DW. Sagittal plane kinematics of a mobile bearing unicompartmental knee arthroplasty at ten years. J Arthroplasty 2004;19:590-7.

36. Martin J, Wallace D, Woods D, Carr A, Murray D. Revision of unicondylar knee replacements to total knee replacements. Knee 1995;2:121-5. 